\title{
COPÉRNICO Y SALAMANCA
}

\section{COPERNICUS AND SALAMANCA}

\section{AUTORES}

Benjamín Fernández Blázquez: Catedrático de la Escuela Universitaria de Estadística de la Universidad Complutense de Madrid.

benjamín.fernandez@aol.com

\section{CURRÍCULUM VITAE}

Catedrático de la Escuela Universitaria de Estadística de la Universidad Complutense de Madrid.

\section{RESUMEN}

Para destacar los eventos y protagonistas de este milenio que se extingue, lejos de la urgencia que determinan estas fulgurantes fechas, que tal vez implican ausencia de ponderación o carencia de alguna variable relevante, es de subrayar que hace poco más de tres años, el laureado diario: Washinton Post, haciendo un análisis desde el año mil, resaltó unos cuantos personajes en diferentes ramas, y eligió como científico más sobresaliente a Copérnico, precediendo a Einstein y Galileo.

\section{PALABRAS CLAVE}

Copérnico - Salamanca - Científicos 


\begin{abstract}
To highlight the events and characters of this millennium is extinguished, away from the emergency flashing determine these dates, which may imply the absence of any weight or lack of relevant variable is to emphasize that a little over three years, the laureate diary: Washington Post, by an analysis from the first millennium, highlighted a few characters in different branches, and chose as most outstanding scientist Copernicus, Galileo and Einstein preceding.
\end{abstract}

\title{
KEY WORDS
}

Copernicus - Salamanca - Scientists

Para destacar los eventos y protagonistas de este milenio que se extingue, lejos de la urgencia que determinan estas fulgurantes fechas, que tal vez implican ausencia de ponderación o carencia de alguna variable relevante, es de subrayar que hace poco más de tres años, el laureado diario "Washinton Post", haciendo un análisis desde el año mil, resaltó unos cuantos personajes en diferentes ramas, y eligió como científico más sobresaliente a Copérnico, precediendo a Einstein y Galileo.

La teoría de heliocentrismo propugnada por Copérnico, estuvo durante décadas colapsada en la emergente Europa de los Estados; universidades como Zurich, Rostok y la Sorbona condenaron la teoría copernicana siguiendo los dictámenes de la Santa Congregación que la rechazaba "por absurda y formalmente herética". Por 
suerte, hubo honrosas excepciones como la Universidad de Salamanca en la que la ciencia astronómica era enseñada por médicos dado que se pensaba que los cuerpos celestes influían en la vida del hombre. El estatuto de 1562 de la Universidad salmantina, la primera del mundo que enseñó los descubrimientos copernicanos, decía: "En astronomía, se lean libros de Euclides y el Almagesto o Copérnico al voto de los oyentes", y otro estatuto de 1594 prescribía: "El segundo quadrienio léase a Copérnico y las tablas plutérnicas en la forma dada", recogiendo las demostraciones de Diego de Zúñiga que en su comentario al Libro de Job, "probó la concordancia del sistema copernicano con las Sagradas

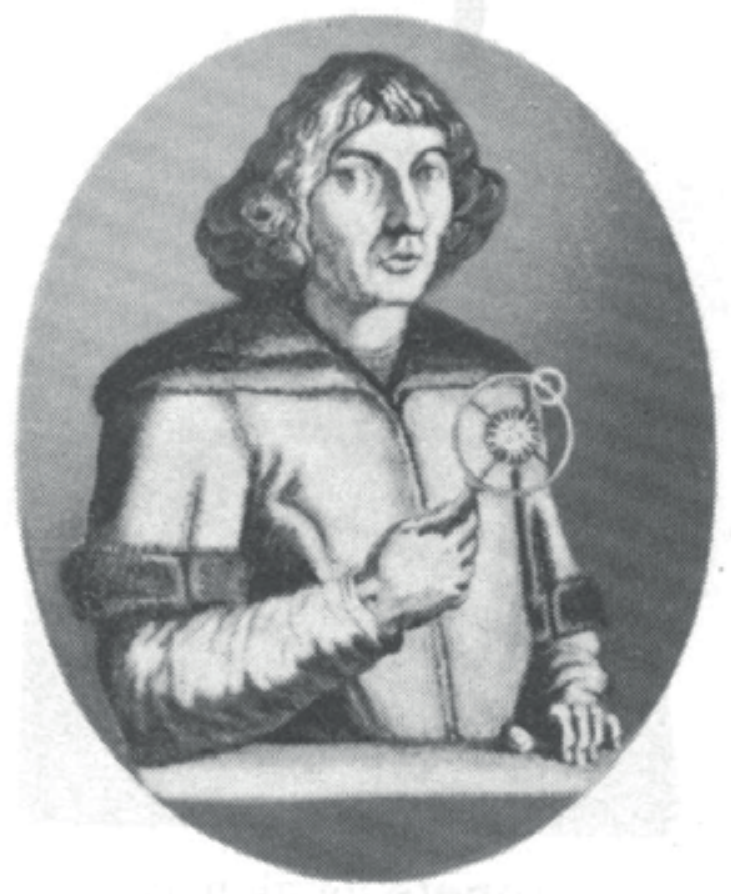

Nicolás COPÉRNICO Escrituras".

Pocos de los manuscritos de Nicolás Copérnico han sobrevivido, guerras saqueos y devastaciones convergieron en su destrucción. Pero quedó lo más importante, su teoría, el nuevo sistema del mundo; según Kesten "la mayor revolución intelectual de la historia de la humanidad". El punto esencial de su investigación era la tesis que hacía al Sol el centro de los planetas, entre ellos la Tierra. Copérnico construyó un nuevo modelo del mundo, el heliocentrismo y creó los fundamentos para una nueva visión del universo. Goethe escribía: "entre todos los descubrimientos no hay nada que haya impresionado a la mente humana como la teoría del sabio polaco; no es extraño que el mundo tratara por todos los medios de rechazar una ciencia que autorizaba a sus seguidores a tener una libertad de visión y audacia de opiniones desconocidas hasta entonces". 
Nicolás Copérnico nació en 1473 en la ciudad polaca de Tórun, a orillas del legendario Vístula, en una época que se atisbaba el renacimiento confundiéndose el hombre y el mundo, a la par que la imprenta de la dorada Cracovia lograba que el pensamiento humano se esparciese por el mundo como un meteoro.

A los 18 años se trasladó a la Universidad de Cracovia, de las más prestigiosas de Europa, justo cuando Cristóbal Colón, otro europeo dotado de una visión más amplia que sus contemporáneos alcanzaba las costas de un nuevo mundo reduciendo el horizonte del planeta, inconmensurable hasta entonces. Copérnico encontró en Cracovia la ciencia en su apogeo y recibió el estímulo para su investigación astronómica a la vez que germinaban sus concepciones científicas.

El Alma Mater cracoviana, según el documento de su fundación "tenía que producir varones insignes en la madurez, y magníficos por el adorno de sus virtudes". En el otoño de 1495 Copérnico dio por terminados sus estudios en esta Universidad y al año seguido se dirigió a Italia para graduarse en Bolonia y Padua doctorándose en Ferrara. Al abandonar la soleada Italia tenía 30 años. De allí pasó a la otra ciudad determinante de su vida, la brumosa Frombork. Aquí desarrolló sus teorías que se formalizaron en la gran obra "De Revolutionibus" aunque su publicación no viera la luz hasta el año de su muerte, acontecida en la primavera de 1543.

Mientras tanto, las teorías copernicanas despertaron no poca resistencia e incluso hostilidad. Eran inconcebibles para muchas de las mentes de entonces, acostumbradas a esquemas determinados que conforme a las Sagradas escrituras, concebían el orden de la Tierra y del Sol como inmutables.

Nicolás Copérnico, sabio y humanista se ocupó en su laboriosa vida de numerosos asuntos teniendo como marco y fondo las ciudades polacas sobre todo la universitaria Cracovia que aún guarda muchas similitudes con Salamanca. Pero 
siempre miraba al firmamento en las noches de los brillantes cielos del Vístula, y con los ojos fijos transformó el orden del mundo de su época y al actual le abrió el camino de las estrellas. 